\title{
QtI Mapping of Clavibacter Michiganensis Subsp. Michiganensis (cmm) Resistance Originating from Solanum Pimpinellifolium g1.1554
}

\section{Yusuf Sen ( $\square$ ysf.sen07@gmail.com)}

Wageningen UR PRI: Wageningen University and Research Wageningen Plant Research https://orcid.org/0000-0001-7981-7758

Mary Jane Manrique

Wageningen UR PRI: Wageningen University and Research Wageningen Plant Research

Aylin Kabaş

Akdeniz Üniversitesi: Akdeniz Universitesi

Richard G.F. Visser

Wageningen UR PRI: Wageningen University and Research Wageningen Plant Research

\begin{abstract}
A.W.(Sjaak van Heusden
Wageningen Universiteit en Researchcentrum Plant Research International BV: Wageningen University and Research Wageningen Plant Research
\end{abstract}

\section{Research Article}

Keywords: Clavibacter, S. pimpinellifolium, Infinium array, Multi-trait analysis, QTL to candidate genes

Posted Date: March 16th, 2021

DOI: https://doi.org/10.21203/rs.3.rs-292564/v1

License: (c) (i) This work is licensed under a Creative Commons Attribution 4.0 International License. Read Full License 


\section{Abstract}

Bacterial canker of tomato, caused by Clavibacter michiganensis subsp. michiganensis ( $\mathrm{Cmm})$, is considered the most serious bacterial threat in tomato and causes large damages in production areas. Worldwide, $\mathrm{Cmm}$ is subjected to quarantine regulations. There is no cultivar on the market containing $\mathrm{Cmm}$ resistance. A mapping study was done in order to identify Quantitative Trait Loci (QTL) for resistance in a cross between Solanum lycopersicum and S. pimpinellifolium GI.1554, a wild relative of tomato. Besides wilting, symptoms like stem discoloration and bacterial titer were considered. Using single trait and multi-trait approaches, we have identified five QTL regions that are associated with wilting, stem discoloration and bacterial titer in three different environments. These QTLs can be used in breeding programs to develop cultivars with higher levels of resistance.

\section{Key Message}

Clavibacter michiganensis subsp. michiganensis $(\mathrm{Cmm})$ is a complex QTL and we have identified five QTL regions that are associated with wilting, stem discoloration and bacterial titer in three different environments.

\section{Introduction}

Clavibacter michiganensis subsp. michiganensis $(\mathrm{Cmm})$ is a gram positive plant bacteria causing bacterial canker in tomato and is considered to be the most harmful bacteria in tomato (de Leon et al. 2008). Symptoms appear as unilateral wilting and at a later stage the whole plant wilts and dies. Besides wilting, stem canker and stem discoloration are symptoms of this disease. Cmm is a seed transmitted disease and even a few infected seeds (one to five seeds per 10,000) can result in a serious epidemic in the field (Chang et al. 1991). Cmm is considered as a quarantine organism and seed companies have to take special precautions to prevent the presence of $\mathrm{Cmm}$ to be able to sell seeds. A good level of $\mathrm{Cmm}$ resistance might reduce some of the problems but there are two kinds of demands to be met: those of the breeders and those of the growers. Breeders would like to have a resistance source that does not allow the growth of a single bacteria in order to be able to sell their seeds. However, for growers, this is not an absolute requirement and a cultivar with a good resistance level, but still some bacterial growth, might already be sufficient and will be a kind of insurance that losses due to a $\mathrm{Cmm}$ outbreak will not be significant. $\mathrm{Cmm}$ is not considered a serious disease by some breeders because they think that good clean management practices will prevent outbreaks, but still in practice outbreaks occur continuously (personal communication with growers) and new varieties containing a good level of $\mathrm{Cmm}$ resistance certainly have an added value in conventional and organic farming. Breeding for bacterial canker resistance in tomato is already going on for almost 50 years (Elenkov 1965 ). A partial resistant variety has been described (Emmatty and John 1973) but this resistance has never been used in the development of new partial resistant varieties. Without sufficient resistance in tomato varieties it was necessary to screen crossable wild species of tomato for resistance (Thry 1967; Thry 1971). After identifying resistance in Solanum arcanum (LA2157) a genetic analysis has been elaborated using intra- and interspecific crosses. In the intraspecific cross five QTL regions on chromosomes 1, 6, 7, 8 and 10 were identified (Sandbrink et al. 1995) and the interspecific crosses revealed 3 QTLs on chromosomes 5, 7 and 9 (van Heusden et al. 1999). In other interspecific crosses between $S$. lycopersicum and S. habrochaites (LA407) at least 2 QTLs, on chromosomes 5 and 7, were found (Kabelka et al. 2002).

Wild species of tomato are a good source to enlarge the genetic diversity in the gene pool of commercial tomato. In a screening for resistance (Sen et al. 2012) found a S. pimpinellifolium (G1.1554) accession with a good resistance level. S. pimpinellifolium is a closely related wild species of tomato and is easily crossable with cultivated tomato (Peralta et al. 2008). Finding resistance genes/QTLs in different sources will make it possible to combine genes from different sources with possible different mechanisms which might give a higher level of resistance. A good phenotyping method, a sufficiently large population with ample opportunities for reproducing screenings and a high density linkage map are the necessary tools to do good mapping studies. To know the QTL x environment effect, it is necessary to do screenings in different environments.

We have used a very well genotyped recombinant inbred line (RIL) population derived from S. lycopersicum cv moneymaker and $S$. pimpinellifolium G1.1554 (Voorrips et al. 2000). For bacterial quantification, we have used a TaqMan PCR assay (Sen et al. 2012). The RIL population was phenotyped in three different environments; namely Dutch greenhouse in winter, Dutch greenhouse in summer and in a greenhouse in spring in Antalya, Turkey. QTL hot spots and QTLxE interactions for several traits were found.

\section{Materials And Methods Plant material and environments}

One hundred recombinant inbred lines derived from a cross between S. lycopersicum cv. Moneymaker and S. pimpinellifolium GI.1554 were used for resistance screenings (Table 1). We screened in three different environments (Table 2).

Table 1 
Genetic map based on a RIL population derived from a cross between S. lycopersicum cv. Moneymaker and S. pimpinellifolium G1.1554 .

\begin{tabular}{|lll|}
\hline Chromosome & Number of linkage groups & Average cM distance between markers \\
\hline 1 & 2 & 1.3 \\
\hline 2 & 1 & 1.2 \\
\hline 3 & 3 & 2.2 \\
\hline 4 & 1 & 1.4 \\
\hline 6 & 1 & 1.7 \\
\hline 7 & 1 & 1.3 \\
\hline 8 & 1 & 2.7 \\
\hline 9 & 2 & 2.1 \\
\hline 10 & 1 & 1.1 \\
\hline 11 & 2 & 3.0 \\
\hline 12 & 1 & 1.2 \\
\hline
\end{tabular}

Table 2

Screening conditions and scored phenotypic traits of the recombinant inbred population.

\begin{tabular}{|lllllll|}
\hline \multicolumn{2}{|l}{ Screening conditions } & & & \multicolumn{3}{l|}{ Measured traits } \\
\hline Environments & Population size & Growing conditions & Bacterial strain & Wilting & Stem dis- coloration & Bacterialtiter \\
\hline Dutch winter & 100 & Soilless & Cmm 542 & done & done & done \\
\hline Dutch summer & 80 & Soilless & Cmm 542 & done & done & done \\
Antalya & 100 & Soil & Mix of strains & done & not done & not done \\
\hline
\end{tabular}

The first environment was a greenhouse in winter in the Netherlands where outside conditions are cold $\left(-10\right.$ to $\left.10{ }^{\circ} \mathrm{C}\right)$, cloudy and shortdays. The second environment was a greenhouse in Dutch summer when it is relatively warmer $\left(10\right.$ to $\left.25^{\circ} \mathrm{C}\right)$ and long days that might even be sunny. A third screening was done in a greenhouse in Antalya, in the south of Turkey where the growing season is from January to May with temperatures varying from 5 to $30^{\circ} \mathrm{C}$ and at least half of the season is sunny. In the first and second screening, conditions in the greenhouse were controlled $\left(18{ }^{\circ} \mathrm{C}\right.$ at night and $24^{\circ} \mathrm{C}$ at day with $60 \%$ humidity) whereas in the third environment this was not the case. In the first and second environment, each line and parents were represented by 4 plants, in the third environment each line and parent was represented by 8 plants and 2 control plants.

\section{Disease test}

In the Netherlands we have used the aggressive bacterial strain Cmm542, in Turkey we have used a mix of 14 local aggressive strains of which specificity is not known. Inoculation was done at the sixth leaf stage by removing the second leaf with scissors and injecting $5 \mu$ l of $10^{6} \mathrm{cfu} / \mathrm{ml}$ bacterial suspension in the wound. In the first and second environment, after inoculation, plants were kept for one week under high relative humidity (100\%), then conditions were changed to $60 \%, 12$ hours daylight, $24^{\circ} \mathrm{C}$ day and $18^{\circ} \mathrm{C}$ night temperature. In Turkey ( $3^{\text {rd }}$ environment) plants were kept under greenhouse conditions after inoculation. Wilting symptoms were recorded using the following scale: 0.5 stands for $12.5 \%$ wilting, 1 for $25 \%$ and scale continues until $100 \%$ wilting. No symptoms, score $=0$ and when the whole plant is wilted and dead, score $=4$. The final wilting symptoms were recorded at 65 days after inoculation. Stem discoloration was measured on the inoculation area of the stem after the experiment finished based on following scale: 0.5 scale was used for each $12.5 \%$ discoloration stem clean, score $=0$; and stem is totally rotten, score $=4$. 


\section{Quantification of bacteria by TaqMan PCR}

To quantify bacteria, three plants from each line and 3 parts of each plant, hereafter refered to as lower, middle part and upper part, were used. The extraction of bacteria from this material was done using PBS buffer (3 times the weight of the stem part). DNA extraction was done using the Quick Pick SML Plant DNA purification kit provided by Bio-Nobile in combination with a Kingfisher processor and followed by a purification step on a PVPP column. RT-PCR amplification was done as follows; The $25 \mu$ reaction includes $10 \mu$ DNA template, $12,5 \mu$ l 10x Takara mix, 0,5 $\mu$ l Rox and $2 \mu \mathrm{l}$ mix of $4 \mu \mathrm{M}$ Forward primer (GGG GCC GAA GGT GCT GGTG), $4 \mu \mathrm{M}$ Reverse primer (CGT CGC CCG CCC GCTG) and $1 \mu \mathrm{M}$ TaqMan probe (modified) (6-FAM/TGG TCG TCC /ZEN/TCG GCG CC/IABkFQ) (Berendsen et al. 2011). The real-time PCR temperature regime was as follows: 95 ${ }^{\circ} \mathrm{C}$ for 30 seconds followed by 50 cycles of $95^{\circ} \mathrm{C}$ for 3 seconds and $60^{\circ} \mathrm{C}$ for 35 seconds using a Bio-Rad CFX thermocycler. To obtain a standard curve, 3 independent replications of ten-fold serial dilutions of bacteria wereused as a template and a water control was included as negative control.

\section{Genetic map}

Custom-made Infinium Bead arrays containing 5528 SNPs were used for genotyping the population (Viquez- Zamora et al. 2013). A genetic map was constructed using Joinmap 4.1 software (Stam, 1993) using regression algorithm with Kosambi mapping function.

\section{QTL analysis}

Data were analyzed by two approaches; single trait single environment and multitrait single environment. Single trait single environment analysis of data was done by MapQTL 6.0 software (Van Oojien et al. 2009) using interval mapping. In order to convert scale type data to continuous style data that allow interval mapping, data were transformed to log scale prior QTL analysis. The Q-Q plot test was used to inspect the distribution of residual data. For interval mapping, a permutation test (10000 times) was done to determine the genome wide threshold for QTL detection. The logarithm-of-odds (LOD) profiles from interval mapping were inspected and the marker closest to each LOD peak was selected as cofactor and the backward elimination procedure was used to select the significant cofactors. This backward elimination procedure was performed until stable cofactor subsets had been obtained. Remaining cofactors were used for further rMQM mapping analysis. For multi-trait single environment analysis, data were standardized according to formula: $\mathrm{X}_{\mathrm{A}}=(\mathrm{x}-\overline{\mathrm{x}}) / \mathrm{SD}$.

Here each value is subtracted from the mean and divided by the standard deviation. We have used a multi-trait single environment model per environment using GenStatversion 14.0 (International 2011). A mixed model composite interval mapping algorithm was used to detect QTLs assuming QTLs as fixed effects in the model, and an unstructured variance covariance model for the residual multi-normal polygenic effect. Details about models and methods can be found in (International 2011).

\section{Heritability Estimates}

Total genotypic variance were obtained from a one-way random effects analysis of variance using GenStatversion 14.0 (International 2011 ). Total variances was partitioned in two components; variations between lines $(\mathrm{Vg})$ and variation within lines, or error variance (Ve). Broad-sense heritability was $\left(\mathrm{H}^{2}\right)$ estimated using both variances according to the formula;

$H^{2}=V g /(V g+V e / n) n=$ number of replicates.

\section{Retrieving candidate genes}

We have used the Marker2 sequence program (Chibon et al. 2012) to retrieve candidate genes in the QTL hot spot region.

\section{Results}

Wilting symptoms of the overall population were different in each environment. Under Dutch controlled greenhouse conditions and the use of a single aggressive strain, there was a tendency towards higher susceptibility in the winter screenings compared to the summer screenings (Figure 1 , blue vs green). Under uncontrolled conditions in Antalya only 7 lines were partially resistant (Figure 1, red).

In the Dutch screenings the susceptible parent was always the first genotype that totally wilted and the resistant parent showed the highest resistance level. No transgressive segregation was observed for wilting in Dutch winter and Dutch summer environments. In Antalya, where growing conditions were poor and a mix of strains was used, transgressive segregation was observed for wilting and the resistant parent showed 
only a moderate level of resistance. The bacterial concentration in Dutch winter and summer varied between $10^{6}$ and $10^{10}$. A large and significant contrast was found between the parents ( $10 \mathrm{fold})$.

The number of available, polymorphic SNP markers between S. lycopersicum and S. pimpinellifolium was 2497 . After removing all but one of the identically segregating loci and markers with a poor goodness-of-fit in the map, we were able to create a genetic linkage map containing 870 SNP markers in 17 linkage groups corresponding to 12 tomato chromosomes. The total genetic size of our map was $1320 \mathrm{cM}$ and large differences were found in recombination frequencies on chromosomes.

The heritabilities of the different traits were high, between 0.6 and 0.8 , except for the bacterial titer in the upper part in Dutch Summer $\left(h^{2}=0.43\right.$ ). The correlation between traits varied from 0 and 0.8 . In general a moderate correlation was found ranging from 0.3 to 0.4 (Table 3 ).

Table 3

Heritability of traits and correlation between traits.

\begin{tabular}{|c|c|c|c|c|c|c|c|c|c|c|c|c|c|}
\hline Traits & Heritability & & Corre & tion $\mathrm{m}$ & & & & & & & & & \\
\hline 1 Antalya_Wilting & 0.78 & 1 & - & & & & & & & & & & \\
\hline $\begin{array}{l}2 \\
\text { DutchSummer_Stemdiscoloration }\end{array}$ & 0.72 & 2 & 0.01 & - & & & & & & & & & \\
\hline 3 DutchSummer_bacteriatiter_low & 0.78 & 3 & 0.11 & 0.28 & - & & & & & & & & \\
\hline $\begin{array}{l}4 \\
\text { DutchSummer_bacteriatiter_mid }\end{array}$ & 0.64 & 4 & 0.25 & 0.27 & 0.31 & - & & & & & & & \\
\hline $\begin{array}{l}5 \\
\text { DutchSummer_bacteriatiter_upp }\end{array}$ & 0.43 & 5 & 0.12 & -0.04 & -0.06 & 0.47 & - & & & & & & \\
\hline 6 DutchSummer_Wilting & 0.87 & 6 & 0.05 & 0.12 & 0.14 & -0.28 & -0.43 & - & & & & & \\
\hline 7 DutchWinter_Stemdiscolotation & 0.65 & 7 & -0.03 & 0.21 & 0.02 & 0.04 & 0.06 & -0.14 & - & & & & \\
\hline 8 DutchWinter_bacteriatiter_low & 0.59 & 8 & 0.16 & 0.18 & 0.09 & 0.34 & 0.34 & -0.15 & 0.39 & - & & & \\
\hline 9 DutchWinter_bacteriatiter_mid & 0.69 & 9 & 0.21 & 0.19 & 0.16 & 0.40 & 0.43 & -0.11 & 0.36 & 0.82 & - & & \\
\hline 10 DutchWinter_bacteriatiter_upp & 0.66 & 10 & 0.07 & 0.22 & 0.05 & 0.34 & 0.39 & -0.14 & 0.22 & 0.64 & 0.58 & - & \\
\hline \multirow[t]{2}{*}{11 DutchWinter_Wilting } & 0.74 & 11 & 0.26 & 0.47 & 0.23 & 0.28 & 0.14 & 0.33 & 0.34 & 0.44 & 0.38 & 0.41 & - \\
\hline & & & 1 & 2 & 3 & 4 & 5 & 6 & 7 & 8 & 9 & 10 & 11 \\
\hline
\end{tabular}

A single trait QTL analysis yielded in total 7 QTL (Figure 2). No QTL was detected for stem discoloration in any envoriment and no QTL was detected for wilting in Dutch summer. The explained variance of these QTL varied from 12.6 to 34.9 (Table 4). The multi-trait approach identified five regions on five different chromosomes (Chr1, Chr2, Chr7, Chr8 and Chr12) with potentially multiple QTL per region. At most 18 QTLs were identified by this approach. The multi-trait approach detected additional QTL regions on chromosomes 1, 2 and 8 and the explained variance for QTL that were detected varied from 4.5 to 32.5 (Table 4).

Table 4

Chromosome, genetic distance,the physical length and explained variance of each detected QTL for threeCmm related traits in three different environments by single and multi-trait QTL approaches. Genetic distance and the physical lengthof each detected QTL were calculated based on 2-LOD QTL interval confidence level. 


\begin{tabular}{|c|c|c|c|c|c|c|c|c|}
\hline \multirow{3}{*}{ Traits } & \multicolumn{4}{|c|}{ Single trait analysis } & \multicolumn{4}{|c|}{ Multitrait analysis } \\
\hline & Chromosome & $\begin{array}{l}\text { Genetic } \\
\text { distance }\end{array}$ & $\begin{array}{l}\text { Physical } \\
\text { length }\end{array}$ & & Chromosome & $\begin{array}{l}\text { Genetic } \\
\text { distance(cM) }\end{array}$ & $\begin{array}{l}\text { Physical } \\
\text { length }\end{array}$ & \\
\hline & & & $(\mathrm{Mb})$ & $\begin{array}{l}\text { Variance } \\
(\%)\end{array}$ & & & $(\mathrm{Mb})$ & $\begin{array}{l}\text { Variance } \\
(\%)\end{array}$ \\
\hline $\begin{array}{l}\text { Wilting in Dutch winter } \\
\text { environment }\end{array}$ & 2 & 6 & 1 & 13.7 & 1,7 and $8 b$ & 14,11 and 9 & $\begin{array}{l}3.7,0.8 \\
\text { and } 2.2\end{array}$ & $\begin{array}{l}9.3,7.0 \\
\text { and } 6.4\end{array}$ \\
\hline $\begin{array}{l}\text { Stem Discoloration in } \\
\text { Dutch winter environment }\end{array}$ & & & & & 1 and 7 & 14 and 11 & $\begin{array}{l}17 \text { and } \\
0.8\end{array}$ & $\begin{array}{l}7.8 \text { and } \\
4.5\end{array}$ \\
\hline $\begin{array}{l}\text { Bacterial titer in Dutch } \\
\text { winter environment (Lower } \\
\text { part) }\end{array}$ & 7 & 5 & 1.1 & 16.3 & 2 and 7 & 5 and 11 & $\begin{array}{l}1 \text { and } \\
0.8\end{array}$ & $\begin{array}{l}\text { 11.7and } \\
16.3\end{array}$ \\
\hline $\begin{array}{l}\text { Bacterial titer in Dutch } \\
\text { winter environment } \\
\text { (Middle part) }\end{array}$ & 7 and 12 & 18 and 6 & $\begin{array}{l}2.4 \text { and } \\
1\end{array}$ & $\begin{array}{l}21.5 \text { and } \\
12.6\end{array}$ & 2,7 and 12 & 5,11 and 20 & $\begin{array}{l}1,0.8 \\
\text { and } 15\end{array}$ & $\begin{array}{l}9.6,22.4 \\
\text { and } 5.7\end{array}$ \\
\hline $\begin{array}{l}\text { Bacterial titer in Dutch } \\
\text { winter environment (Upper } \\
\text { part) }\end{array}$ & & & & & 7 & 11 & 0.8 & 7 \\
\hline $\begin{array}{l}\text { Wilting in Dutch summer } \\
\text { environment }\end{array}$ & & & & & 1 and $8 b$ & 14 and 9 & $\begin{array}{l}17 \text { and } \\
2.2\end{array}$ & $\begin{array}{l}18.1 \text { and } \\
20.7\end{array}$ \\
\hline \multicolumn{9}{|l|}{$\begin{array}{l}\text { Stem discoloration in } \\
\text { Dutch summer } \\
\text { environment }\end{array}$} \\
\hline \multicolumn{9}{|l|}{$\begin{array}{l}\text { Bacterial titer in Dutch } \\
\text { summer environment } \\
\text { (Lower part) }\end{array}$} \\
\hline $\begin{array}{l}\text { Bacterial titer in Dutch } \\
\text { summer environment } \\
\text { (Middle part) }\end{array}$ & 12 & 5 & 0.2 & 13.3 & 7 and 12 & 11 and 20 & $\begin{array}{l}0.8 \text { and } \\
15\end{array}$ & $\begin{array}{l}11.9 \text { and } \\
14.1\end{array}$ \\
\hline $\begin{array}{l}\text { Bacterial titer in Dutch } \\
\text { summer environment } \\
\text { (Upper part) }\end{array}$ & 7 & 12 & 2.4 & 18.2 & 1 and 7 & 14 and 11 & $\begin{array}{l}17 \text { and } \\
0.8\end{array}$ & $\begin{array}{l}5.4 \text { and } \\
17\end{array}$ \\
\hline $\begin{array}{l}\text { Wilting in Antalya } \\
\text { environment }\end{array}$ & 7 & 20 & 2.4 & 34.9 & 7 & 11 & 0.8 & 32.5 \\
\hline
\end{tabular}

For the major QTL on Chromosome 7 we used the physical position of the SNP markers flanking the QTL(ch07:60289256..61494964) and searched in this $1.2 \mathrm{Mb}$ area for genes. In total 157 genes were found of which 5 belong to the NBS-LRR disease resistance class which might play role in resistance.

\section{Discussion}

Dissecting phenotypic responses into different components makes it possible to understand the mechanisms of resistance better (Firdaus et al. 2011). We have dissected our disease response in three components; wilting, stem discoloration and bacterial titer. To prevent false positive and false negative results, the bacterial titer has been measured in three different parts of the plants. Environmental effects influence the severity of disease symptoms. Plants appear more resistant in conditions where they can grow well (Fig. 1). Based on the involvement of multiple loci and the large GxE effects, we assume that the resistance mechanisms are both morphological and physiological. Our hypothesis is supported by previously published research (Coaker et al. 2002; Coaker et al. 2005).

The SNPInfinium array enabled us to construct a high quality genetic map. Genetic order and physical order of markers was very consistent. The total genetic map size was similar to the KazusaMap (Shirasawa et al. 2010). Cold spots (low recombination rate) were detected in large regions around the centromere and hot spots (high recombination rate) were found outside the centromeric region where genes are more abundant and less repetitive DNA is present (Consortium, 2012). Due to a lack of markers in the recombination hot spot areas some chromosomes were represented by more than one linkage group. Due to the known positions of the SNPs it is possible to look for other SNPs if needed for fine mapping purposes. The genetic dissection of $\mathrm{Cmm}$ resistance in a recombinant inbred line population has revealed several QTL for $\mathrm{Cmm}$ related traits. Previously reported publications also show that several regions were involved in resistance (Sandbrink et al. 1995; Kabelka et al. 2002; Thyr, 1976). The severity of wilting is generally considered as the best indication of resistance. Multi-trait QTL mapping using the three typical Cmm symptoms (wilting, stem discoloration and bacterial titer) showed that QTL are co-localized in regions of chromosome 1, 2, 7, 8 and 12. 
Multi-trait analysis improved the power of analysis and identified additional QTLs on chromosome 1, 2 and 8 but didn't confirm the QTL on Chromosome 2 (Dutch winter wilting) which was detected by the single trait approach.

In general, no QTL with a consistent effect in all environments for all three traits was found. The multi-trait approach revealed that the QTL on Chromosome 7 is stable across the environments for three traits (Table 4). A combination of the QTLs on chromosome 2 (multi-trait analysis) and Chromosome 7 (single and multi-trait analyses) gave a similar wilting as in the resistant parent (data not shown). The QTL on Chromosome 2 was not in the same region as a previously published QTLon Chromosome 2 originating from S. habrochaites (LA407) (Coaker and Francis, 2004). The genomic region on chromosome 7 with several QTL is located quite far from the QTL region which was found on Chromosome 7 that was designated as the most important QTL originating from S. arcanum (LA2157) (van Heusden et al. 1999). The heritability was generally high for all traits (0.43 to 0.87 ), and the sum of the explained variances of the detected QTL didn't explain the whole heritability. This missing heritability can be due to missing QTL and noise in phenotyping. The epistatic interactions of QTL might also be cause of missing heritability (Brachi et al. 2011; Manolio et al. 2009). In the Dutch winter and summer environments, one aggressive strain was used whereas in Antalya a mix of 14 different aggressive strains has been used. Therefore an effect of strain differences in experiments must be considered if gene-to-gene interactions exist. However gene-to-gene interactions are not expected in the $\mathrm{Cmm}$-tomato interaction (Eichenlaub and Gartemann, 2011) thus we ignored the strain effect in our experiment which might have been involved in the instability of QTL across environments.

Multi-trait model QTL analysis takes into account the correlation of traits,in doing so the power of detecting QTL and precision of QTL position can be increased (Banerjee et al. 2008; Malosetti et al. 2008). Multi-trait interval analysis can detect QTL for traits in situations when the heritability is relatively high and the effect of traits is too small to allow detection by single-trait interval mapping (Korol et al. 1995). Traits that were scored in our study are phenotypic responses to bacterial attack, and most probably identical pathways are involved resulting in parameters that are related such as bacterial titer and wilting. Multi-trait analysis can then be better than a single trait analysis. An example are the QTL which were detected on chromosome 2 and 11 (Fig. 2).

Figure 2. a-e: QTL profile of single trait approach. Genetic distance (cM) and physical position of each QTL is shown with number at left side of graph. Horizontal side of the graphshowinga LOD score of QTL. Bar showing 1and 2-LOD intervals of each detected QTL and undetected QTL by single approach but detected by multi-trait approach for this trait. Dashed line showing genome-wide threshold.Green colour represent 'Wilting' trait, red colour represents 'Stem discoloration' trait, brown colour represents 'Bacterial titer' traits and black colour showing multi-trait test analysis intervals. f-g:QTL profile of multi- trait approach. (f) bar shows statistical power (-log10(p)) and QTL that above genomewide threshold (g) bar shows traits in different environments with blue allele from S. pimpinellifolium and red allele from S. lycopersicum parent.

Sometimes the use of multi-trait analysis results in that QTL found with the single trait analysis are not found back. An example of this is the QTL for wilting on Chromosome 2. Differences in findings of QTL with the same data can be the result of the different statistical models involved and/or the inference methods used (single trait QTL mapping is based on a mixture model approach whereas multi-trait analysis is based on a mixed model approach).

QTL for three components (wilting, stem discoloration and bacterialtiter ) were found in several common regions (Table 4) which is an indication for pleiotropy or strong linkage. Fine mapping or QTL cloning may separate these two phenomena. For bacterial titer and wilting, transgressive segregation was observed. Transgression for the level of Cmm resistance has been reported before (Crino et al. 1995; Poysa, 1993).

Transgressive segregation was only observed in Antalya condition. It is generealy accepted that transgression is complementary gene actions which can be visible in recombinant individuals (deVicente and Tanksley, 1993) plus with recessive alleles which came to homozygous state in this population (Loren et al. 1999). Although dominance or overdominance are also thought to be involved in transgression (deVicente and Tanksley, 1993) this was not the case in RIL population since it has almost complete homozygous state. It seems that this transgression has strong environmental effect. The mechanism(s) underlying $\mathrm{Cmm}$ resistance in tomato are still largely unknown. In QTL 7 region, we have identified 5 NBS-LRR genes which might contribute resistance in quantitative respect by residual effect of R gene concept (Rauscher et al. 2010). In the near future we will analyse the resequenced S. lycopersicum cv Moneymaker, S. pimpinellifolium and 60 of the RILs. This might give hints about gene(s) that are involved in the resistance and may give possible mechanisms perspective based on their known or putative function.

\section{Conclusion}

In conclusion, S. pimpinellifolium GI.1554 can be a good source for $\mathrm{Cmm}$ resistance. Other traits than wilting can be considered for screening in order to understand resistance mechanisms better and to identify the most useful and stable QTL. In this study, we have used a well-studied population and QTL analysis was done by two different approaches. Our conclusion is that multi-trait analysis was more powerful than a single trait QTL analysis. Nearly isogenic lines can confirm the effect of those regions in a S. lycopersicum background and fine mapping in the QTL hot spots, especially Chromosome 7, might point to candidate genes which makes it possible to understand the resistance mechanisms better. The QTL from S. pimpinellifolium can be combined with QTL from S. arcanum (LA2157) in order to obtain higher levels of resistance, which are are especially important for growers to prevent devastating outbreaks of $\mathrm{Cmm}$. 


\section{Declarations}

\section{Acknowledgements:}

We are thankful to Marcos Malosetti for helpful advises (Biometris, Wageningen University).

\section{Author contributions statement}

YS and SH designed the research. YS, SH, and RV developed the plant materials and and genetic and data analysis. AK tested materials. YS and $\mathrm{SH}$ wrote the manuscript. All authors reviewed and approved publication of this study.

\section{Compliance with ethical standards}

\section{Conflict of interest}

The authors declare no conficts of interest.

\section{References}

1. Banerjee S, Yandell BS, Yi N (2008) Bayesian Quantitative Trait Loci Mapping for Multiple Traits. Genetics 179(4): $2275-2289$.

2. Berendsen SMH, Koenraadt H, Woudt B, Oosterhof J (2011)The development of a specific Real-Time TaqMan for the detection of Calvibacter michiganensis subsp. michiganensis. APS-IPPC Meeting, Honolulu, Hawaii.

3. Brachi B, Morris GP, Borevitz JO (2011) Genome-wide association studies in plants: the missing heritability is in the field. Genome Biol 12(10).

4. Chang RJ, Ries SM, Pataky JK (1991) Dissemination of clavibacter-michiganensis subsp michiganensis by practices used to produce tomato transplants. Phytopathology 81(10): 1276-1281.

5. Chibon PY, Schoof H, Visser RG, Finkers R (2012) Marker2sequence, mine your QTL regions for candidate genes. Bioinformatics 28(14): 1921-1922.

6. Coaker GL, Meulia T, Kabelka EA, Jones AK, Francis DM (2002) A QTL controlling stem morphology and vascular development in Lycopersicon esculentum X Lycopersicon hirsutum (Solanaceae) crosses is located on chromosome 2. American Journal of Botany 89(12):1859-1866.

7. Coaker G, Francis D (2004) Mapping, genetic effects, and epistatic interaction of two bacterial canker resistance QTLs from Lycopersicon hirsutum. Theor Appl Genet 108:1047-1055.

8. Coaker GL, Willard B, Kinter M, Stockinger EJ, Francis DM (2005) Genetic and proteomic analysis of resistance mediated by Rcm 2.0 and Rcm 5.1, two loci controlling resistance to bacterial canker of tomato. Phytopathology 95(6):S122-S122.

9. Consortium TTG (2012) The tomato genome sequence provides insights into fleshy fruit evolution. Nature 485(7400):635-641.

10. Crinò P, Veroness P, Stamigna C, Chiaretti D, Lai A, Bitti ME, Saccardo F (1995) Breeding for resistance to bacterial canker in Italian tomatoes for fresh market. Acta Hort (ISHS) 412:539-545.

11. deVicente MC, Tanksley SD (1993) QTL analysis of transgressive segregation in an interspecific tomato cross. Genetics 134(2):585-596.

12. de Leon L, Siverio F, Lopez MM, Rodriguez A (2008) Comparative efficiency of chemical compounds for in vitro and in vivo activity against Clavibacter michiganensis subsp michiganensis, the causal agent of tomato bacterial canker. Crop Protection 27(9):1277-1283.

13. Eichenlaub R, Gartemann KH (2011) The Clavibacter michiganensis subspecies: molecular investigation of gram-positive bacterial plant pathogens. Annual review of phytopathology 49:445-464.

14. Elenkov E (1965) Die selektion von tomaten auf resistenz gegen die bakterienwelke. Int Z Landwirt 594-597.

15. Emmatty DA, John CA (1973) Evaluation of resistance to bacterial canker of H2990, a new tomato variety. Plant Disease Reporter 57(7):584586.

16. Firdaus S, Van Heusden A, Harpenas A, Supena EDJ, Visser RGF, Vosman B (2011) Identification of silverleaf whitefly resistance in pepper. Plant Breeding 130(6):708-714.

17. International V (2011) GenStat for Windows 14th Edition VSN International, Hemel Hempstead, UK www.GenStat.co.uk.

18. Kabelka E, Franchino B, Francis DM (2002) Two loci from Lycopersicon hirsutum LA407 confer resistance to strains of Clavibacter michiganensis subsp michiganensis. Phytopathology 92(5):504-510. 
19. Korol AB, Ronin YI, Kirzhner VM (1995) Interval mapping of quantitative trait loci employing correlated trait complexes. Genetics 140(3):11371147.

20. Loren HR, Margaret AA, Robert KW (1999) Transgressive segregation, adaptation and speciation. Heredity 83(4):363-372.

21. Malosetti M, Ribaut J, Vargas M, Crossa J, Eeuwijk F (2008) A multi-trait multi-environment QTL mixed model with an application to drought and nitrogen stress trials in maize (Zea mays L.) 161(1-2):241-257.

22. Manolio TA, Collins FS, Cox NJ, Goldstein DB, Hindorff LA, Hunter DJ, McCarthy MI, Ramos EM, Cardon LR, Chakravarti A et al (2009) Finding the missing heritability of complex diseases. Nature 461(7265):747-753.

23. Peralta I, Spooner D, Knapp S (2008) Taxonomy of wild tomatoes and their relatives (Solanum sect. Lycopersicoides, sect. Juglandifolia, sect. Lycopersicon; Solanaceae). Syst Bot Monogr 84:1.

24. Poysa V (1993) Evaluation of Tomato Breeding Lines Resistant to Bacterial Canker. Canadian Journal of Plant Pathology-Revue Canadienne De Phytopathologie 15(4):301-304.

25. Rauscher G, Simko I, Mayton H, Bonierbale M, Smart C, Grunwald N, Greenland A, Fry W (2010) Quantitative resistance to late blight from Solanum berthaultii cosegregates with R Pi-ber : insights in stability through isolates and environment. Theor Appl Genet 121(8):1553-1567.

26. Sandbrink JM, Vanooijen JW, Purimahua CC, Vrielink M, Verkerk R, Zabel P, Lindhout P (1995) Localization of genes for bacterial canker resistance in lycopersicon-peruvianum using rflps. Theor Appl Genet 90(3-4):444-450.

27. Sen Y, Zhu F, Vandenbroucke H, van der Wolf J, Visser R, van Heusden A (2012) Screening for new sources of resistance to Clavibacter michiganensis subsp. Michiganensis (Cmm) in tomato. Euphytica 1-9.

28. Shirasawa K, Isobe S, Hirakawa H, Asamizu E, Fukuoka H, Just D, Rothan C, Sasamoto S, Fujishiro T, Kishida Y et al. (2010) SNP discovery and linkage map construction in cultivated tomato. DNA research : an international journal for rapid publication of reports on genes and genomes 17(6):381-391.

29. Stam P (1993) Construction of integrated genetic linkage maps by means of a new computer package: Join Map. The Plant Journal 3(5):739-744.

30. Thyr BD (1967) Evaluation of tomato seedlings in greenhouse for resistance to bacterial canker (Corynebacterium Michiganense). Phytopathology 57(10):1009.

31. Thyr BD (1971) Resistance to Corynebacterium michiganense measured in six Lycopersicon accessions. Phytopathology 61:972-974.

32. Thyr BD (1976) Inheritance of Resistance to Corynebacterium michiganense in Tomato. Phytopathology 66:1116-1119.

33. van Heusden AW, Koornneef M, Voorrips RE, Bruggemann W, Pet G, Vrielink van Ginkel R, Chen X, Lindhout P (1999) Three QTLs from Lycopersicon peruvianum confer a high level of resistance to Clavibacter michiganensis ssp michiganensis. Theor Appl Genet 99(6):10681074.

34. Van Oojien JW (2009) Software for the mapping of quantitative trait loci in experimental populations of diploid species Kyazma BV, Wageningen, Netherlands.

35. Viquez-Zamora M, Vosman B, van de Geest H, Bovy A, Visser R, Finkers R, van Heusden A (2013) Tomato breeding in the genomics era: insights from a SNP array. BMC Genomics 14(1):354.

36. Voorrips R, Verkerke W, Finkers R, Jongerius R, Kanne J (2000) Inheritance of taste components in tomato. Acta Physiol Plant 22(3):259-261.

\section{Figures}




\section{Wilting Score of population in three environment}

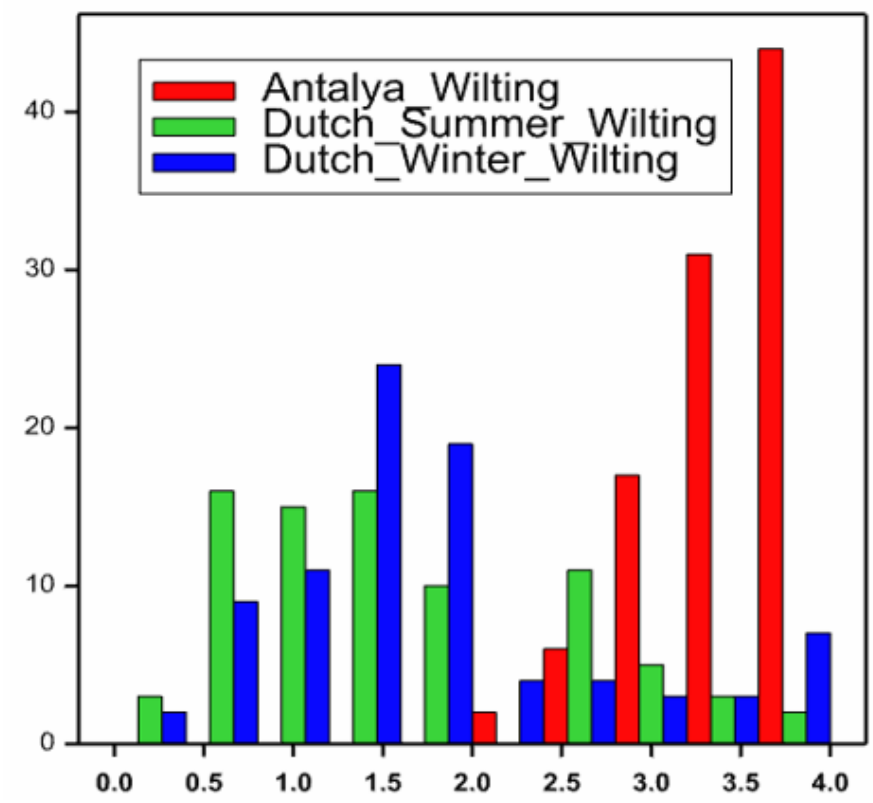

Figure 1

The distribution (before transformation) of wilting in three different environments. Vertical bar shows disease score and horizontal bar shows number of lines for each disease score.
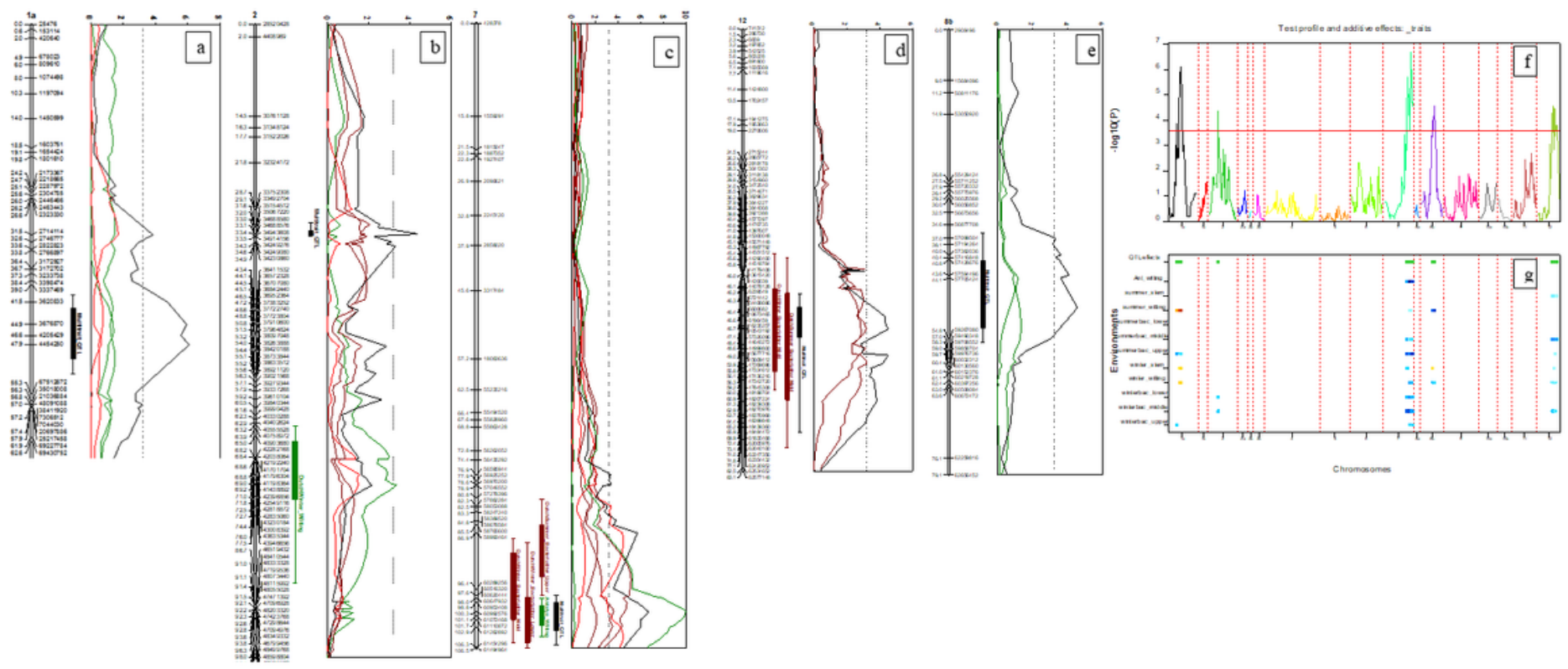

Figure 2

a-e: QTL profile of single trait approach. Genetic distance (cM) and physical position of each QTL is shown with number at left side of graph. Horizontal side of the graphshowinga LOD score of QTL. Bar showing 1and 2-LOD intervals of each detected QTL and undetected QTL by single approach but detected by multi-trait approach for this trait. Dashed line showing genome-wide threshold.Green colour represent 'Wilting' trait, red colour represents 'Stem discoloration' trait, brown colour represents 'Bacterial titer' traits and black colour showing multi-trait test analysis intervals. $f-g: Q T L$ profile of multi- trait approach. $(\mathrm{f})$ bar shows statistical power $(-\log 10(\mathrm{p}))$ and QTL that above genomewide threshold $(\mathrm{g})$ bar shows traits in different environments with blue allele from S. pimpinellifolium and red allele from S. lycopersicum parent. 